\title{
Another way of deriving the ring current decay time during disturbed periods
}

\author{
Marta M. Zossi de Artigas and José Roberto Manzano \\ Laboratorio de Ionosfera, Instituto de Física, Facultad de Ciencias Exactas y Tecnología, \\ Universidad Nacional de Tucumán, Argentina
}

\begin{abstract}
Coupling parameter, $\epsilon$, and the total energy dissipated by the magnetosphere, $U_{T}$, are determined for six disturbed periods, following three known criteria for $U_{T}$ computation. It is observed that $U_{T}$ exceeds $\in$ for $D s t<-90 \mathrm{nT}$, for all models. Differences between models reside on the estimated values for the particles' life time in the equatorial ring current. The values of $\tau_{R}$, used in the models, are small during the main phase of the disturbance, in disagreement with the charge exchange life time of the majority species, $\mathrm{H}^{+}$and $\mathrm{O}^{+}$. Based on this conclusion, a different criterion to calculate $\tau_{R}$ is proposed, differentiating the different stages of the perturbation. $\tau_{R}$ is calculated, for the main phase of the storm, from the rate of energy deposition estimation, $Q$, in the ring current. For $D s t$ recovery phase, the values are obtained from a ring current decay law computation. The $U_{T N U}$ calculated, physically more coherent with the processes occurring during the event, is now smaller than expected. In this sense, it is understood that the power generated by the solar wind-magnetosphere dynamo, should also be distributed in the inner magnetosphere, auroral zones and equatorial ring current, as in the outer magnetosphere, plasmoids in the tail shot in antisolar direction. A further adjustment of $\epsilon$, with the Chapman-Ferraro distance, $l_{0}$, variable, has been made. Although the results, improve the estimation of $\epsilon$, they are still smaller than $U_{T}$, except $U_{T N U}$, for some disturbed periods. This result indicates the uncertainty in the computation of the input energy, by using the many expressions proposed in the literature, which are always presented as laws proportional to a given group of parameters, with an unknown factor of proportionality, which deserves more detailed physical analysis.
\end{abstract}

Key words magnetosphere - substorms - ring current - plasmoids

\section{Introduction}

The solar wind energy input generated by the solar wind-magnetosphere dynamo coupling can be estimated using several functions. One of those was introduced by Perreault and Akasofu (1978) as the parameter $\in$ given by

$$
\epsilon=v B^{2} \sin ^{4}(\Theta / 2) l_{0}^{2}
$$

where $v$ is the solar wind speed, $B$ the interplanetary magnetic field (IMF) magnitude, $\Theta$ the polar angle of the IMF projected on the $Y-Z$ plane in the GSM coordinate system, and $l_{0}=7$ $R_{E}\left(R_{E}=\right.$ Earth radius).

The total magnetospheric energy dissipation parameter, $U_{T}$, is given by different processes. Part of the energy dissipated in the inner magnetosphere, is deposited in the ring current belt, $U_{R}$. Another part is partially dissipated as joule heating energy, $U_{J}$, and partially as auroral particles injection, $U_{P}$ (Perreault and Akasofu, 1978). According to Akasofu (1981), $U_{T}$ may be written as

$$
U_{T}=\alpha\left(\partial D / \partial t+D / \tau_{R}\right)+\beta A E
$$

where $D$ is the absolute value of the $D s t$ index 
corrected for the solar wind dynamic pressure changes, $\tau_{R}$ is the ring current decay time, $A E$ the auroral electrojet index, and $\alpha$ and $\beta$ are constants equal to $4 \times 10^{20}$ erg $(\mathrm{nT})^{-1}$ and $3 \times 10^{15}$ erg $(\mathrm{nT} \mathrm{s})^{-1}$, respectively.

The most uncertain parameter in $U_{T}$ formulation, is $\tau_{R}$. Several methods have been suggested to introduce $\tau_{R}$ in that equation. We will only mention three of them; the first due to Akasofu (1981), who considers $\tau_{R}$ depending on $\epsilon$, the second due to Vasyliunas (1987), who makes $\tau_{R}$ independent of $\epsilon$ but a function of magnetospheric energy output $U_{T}$, and the last due to Gonzalez et al. (1989) who assume $\tau_{R}$ depending on Dst.

In this paper, we first assume that the coupling function $\epsilon$ with $l_{0}$ constant, is a good estimation of the energy input and we handle the above three methods for six selected disturbed periods, together with the new proposed criterion, here introduced, to calculate $\tau$, aiming at a better agreement with experimental results.

As a second step, we consider that $l_{0}$ in $\epsilon$ function is not a constant. According to Roederer (1987):

$$
l_{0}=\left\{M_{E}^{2} / \mu_{0} \rho v^{2}\right\}^{1 / 6}
$$

where $M_{E}$ is the earth magnetic momentum and $\rho v^{2}$ is the solar wind dynamic pressure.

\section{Models and results}

According to Zwickl et al. (1987), Akasofu's criterion to introduce $\tau_{R}$ is given by

$$
\begin{array}{rlrl}
\tau_{R} & =20 \mathrm{~h} & \epsilon & \leq 10^{18} \mathrm{erg} \mathrm{s}^{-1} \\
& =2 & 10^{18}<\epsilon \leq 5 \times 10^{18} \\
& =1 & 5 \times 10^{18}<\epsilon \leq 10^{19} \\
& =0.5 & 10^{19}<\epsilon \leq 5 \times 10^{19} \\
& =0.25 & 5 \times 10^{19}<\epsilon
\end{array}
$$

Vasyliunas (1987), considering that there is a range of $\epsilon$ for which $\tau_{R}$ tends to a power law, reformulates $\tau_{R}$ as a function of $U_{T}$ instead of $\epsilon$, but for $v=1 / \tau_{R}$ :

$$
\begin{array}{rlrl}
v & =0.05 \mathrm{~h}^{-1} & U_{T} \leq 10^{18} \mathrm{erg} \mathrm{s}^{-1} \\
& =0.33\left[U_{T} / 10^{18}\right]^{0.6} & 10^{18} & <U_{T} \leq 6.4 \times 10^{19} \\
& =4 & 6.4 \times 10^{19} & <U_{T}
\end{array}
$$

Gonzalez et al. (1989) assume three domains of Dst in order to search for the best values of $\tau_{R}$ from the correlation study between $U_{T}$ and different coupling functions. The chosen $D s t$ intervals are:

$$
\begin{aligned}
& D s t \geq-50 \mathrm{nT} \\
&-120 \mathrm{nT} \leq D s t<-50 \mathrm{nT} \\
& D s t<-120 \mathrm{nT}
\end{aligned}
$$

The authors worked with different sets of $\tau_{R}$ values: 1) $\tau_{R}$ constant for different $D s t$ ranges, resulting in very low correlation coefficients $(<0.5) ; 2)$ sets of $\tau_{R}$ values decreasing when $|D s t|$ increases. In this case, all coupling functions show the best correlation coefficients for the sets of $\tau_{R}$ values $(4,0.5,0.5)$ and $(4,0.5$, $0.25)$. Gonzalez and co-workers restricted this analysis to the main phase of the disturbance.

In this paper, six disturbed periods have been analyzed (table I). The parameter $U_{T}$ has been calculated for the above methods, i.e. Akasofu's $\left(U_{T A K}\right)$, Vasyliunas' $\left(U_{T V A S}\right)$ and that suggested by Gonzalez and co-workers $\left(U_{T G O N}\right)$. The results of the application of these methods are compared with each other and with $\in$.

Figures 1a-f show the results in the different

Table I. Disturbed periods analyzed in this paper.

$\begin{array}{ll}\text { January 29-31, 1978 } & \text { Dst }<-100 \mathrm{nT} \\ \text { August 29-30,1979 } & \text { Dst }<-150 \mathrm{nT} \\ \text { October 20-23,1981 } & \text { Dst }<-200 \mathrm{nT} \\ \text { March 1-2, 1982 } & \text { Dst }<-220 \mathrm{nT} \\ \text { November 23-25, 1982 } & \text { Dst }<-220 \mathrm{nT} \\ \text { February 10-13,1984 } & \text { Dst }<-60 \mathrm{nT}\end{array}$



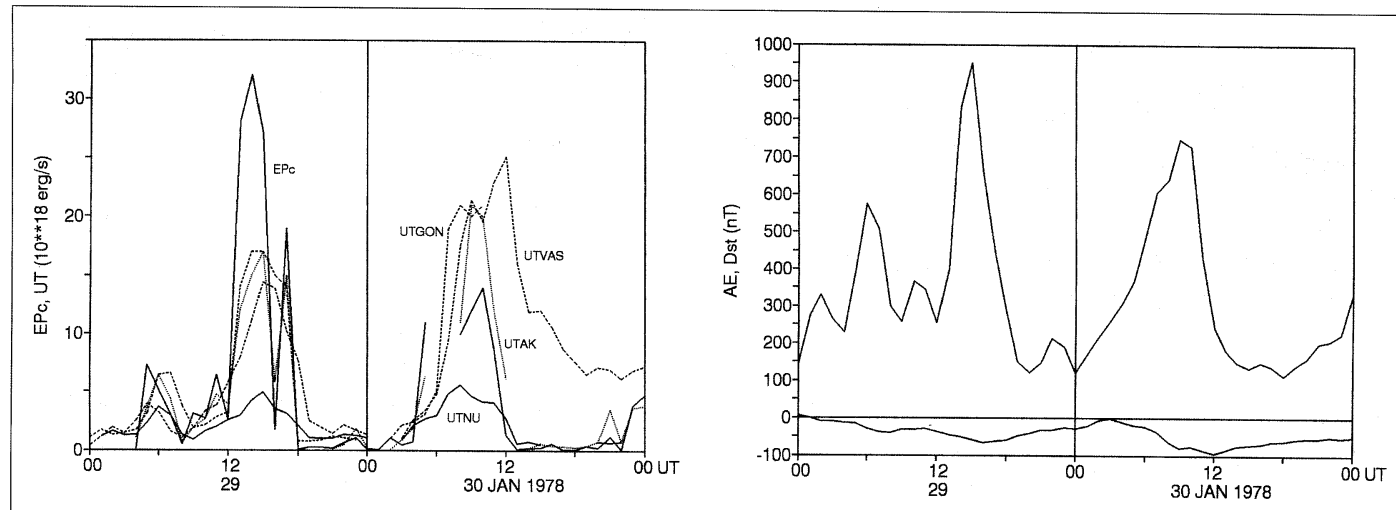

(a)
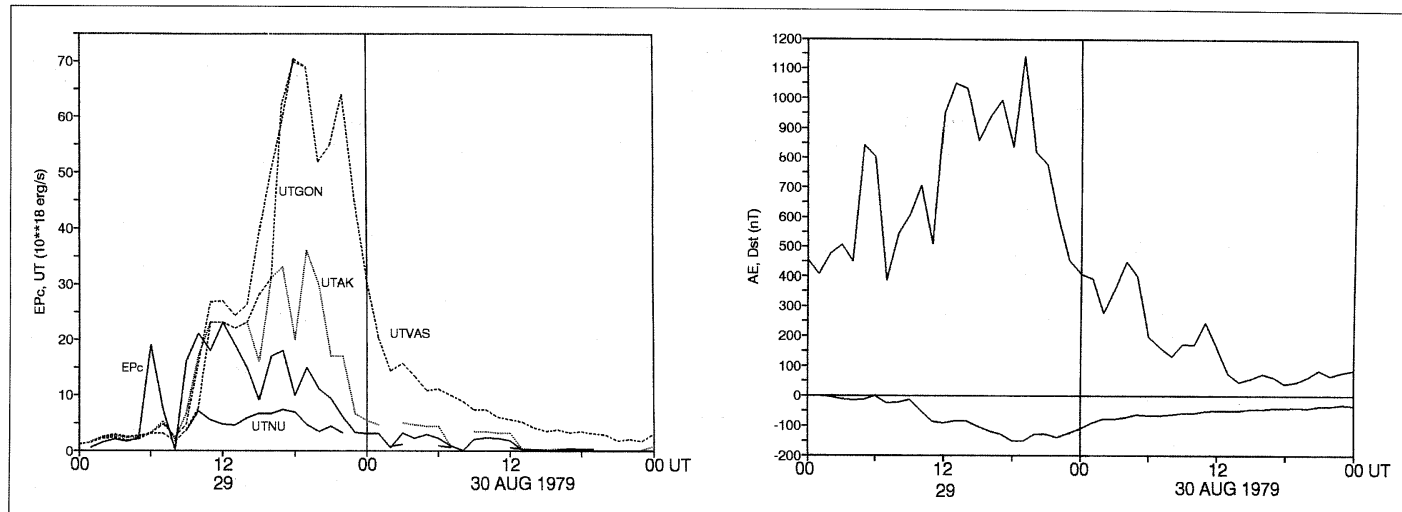

(b)
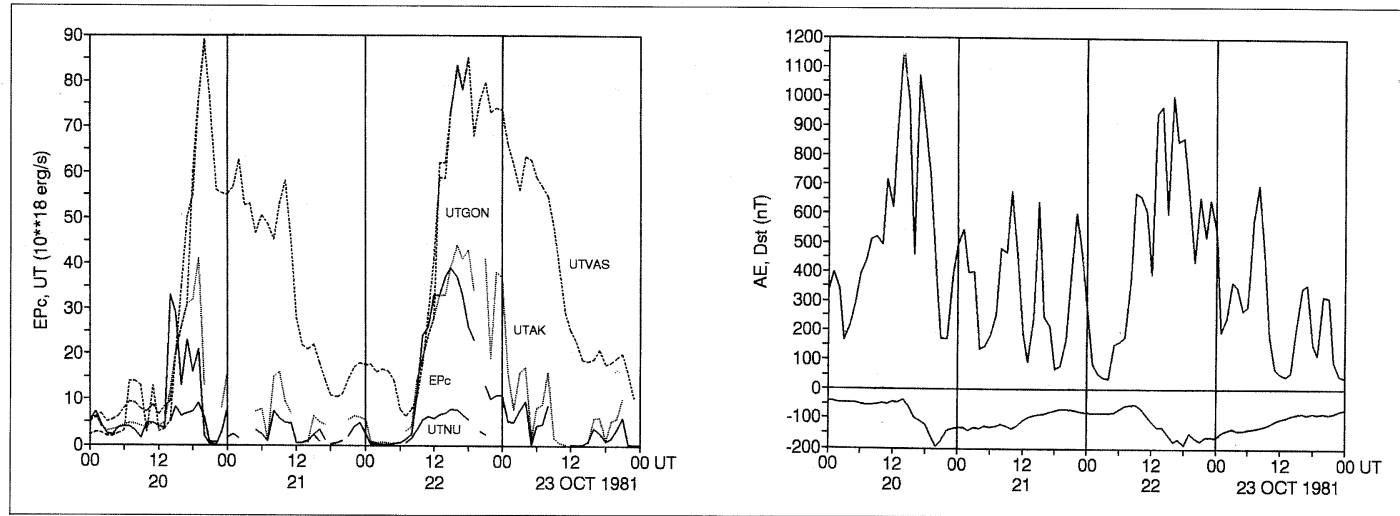

(c)

Fig. 1a-c. $\varepsilon\left(E P_{c}\right)$, the total magnetospheric dissipation parameter $U_{T}$, using the four methods indicated, $A E$ and Dst geomagnetic indices for: a) January 29-30, 1978; b) August 29-30, 1979; c) October 20-23, 1981. 

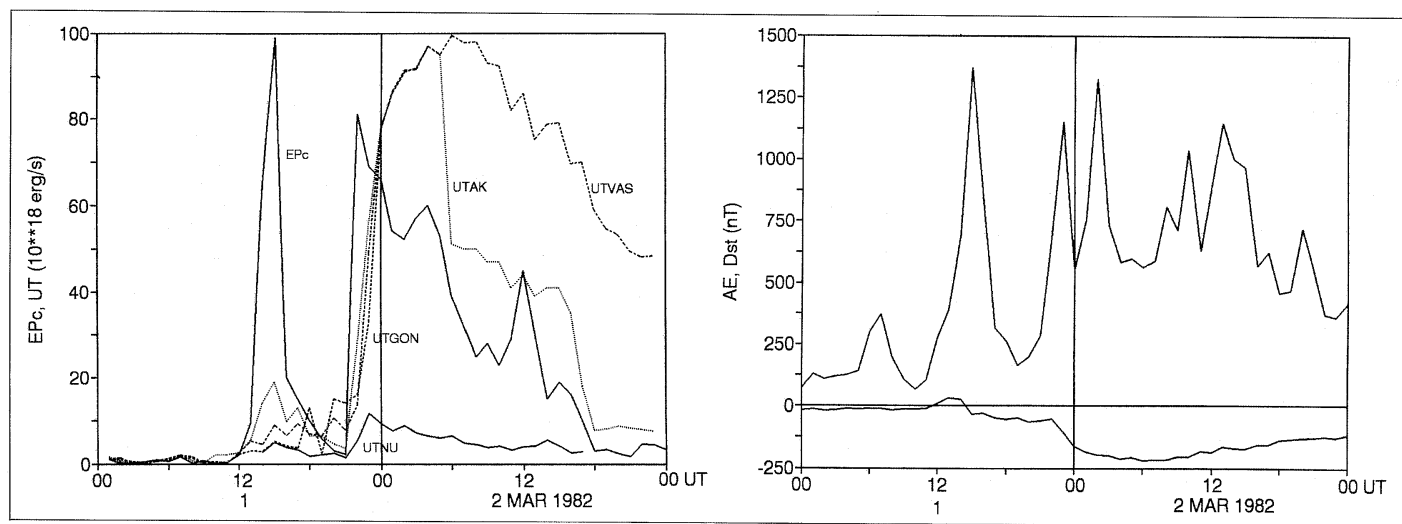

(a)
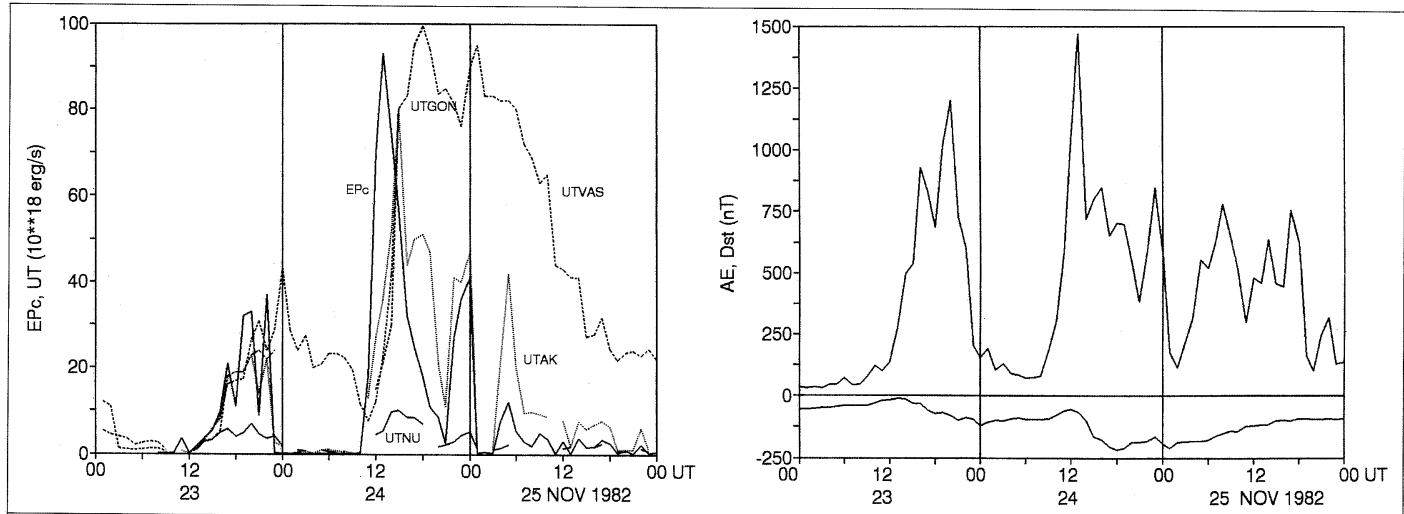

(อ)
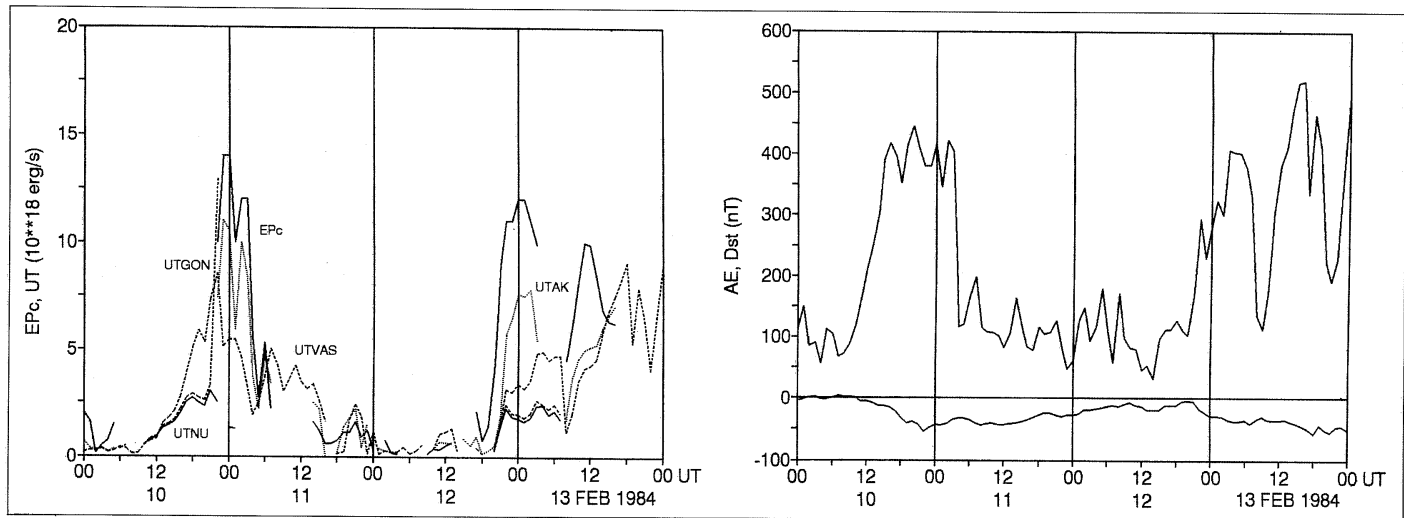

(1)

Fig. 1d-f. $\varepsilon\left(E P_{c}\right)$, the total magnetospheric dissipation parameter $U_{T}$, using the four methods indicated, $A E$ and Dst geomagnetic indices for: d) March 1-2, 1982; e) November 23-25, 1982; f) February 10-13, 1984. 
disturbed periods, respectively. These figures also show the variation of the equatorial geomagnetic index, Dst, for the same periods. It can be clearly seen that for $|D s t|<90 \mathrm{nT}$, the three methods give values of $U_{T}$ smaller than $\epsilon$, but when Dst goes below $-90 \mathrm{nT}, U_{T}$ «jumps» to unexpected values much greater than $\in$. This result, very difficult to justify from a physical point of view, could be related to two possible reasons: first, a fault in the modeling of $\tau_{R}$ implicating the need for a revision of criteria to derive this parameter, and second, no consideration is taken of the substantial part of the magnetospheric energy dissipated tailward from the plasmasheet recon- nection region with the generation of the socalled plasmoids (Mishin, 1991).

The ring current decay time values, $\tau_{R}$, proposed by the different models, are small at the time of maximum disturbance. Those values do not agree with the charge exchange lifetimes (predominant loss process) of the major species in the equatorial ring current: $H^{+}$and $O^{+}$(table II).

\section{A new approach}

Based on those results, in this paper we analyze the ring current decay time, $\tau$, during the

Table II. Charge exchange lifetimes in hours (from Hamilton et al., 1988).

\begin{tabular}{cccccc}
\hline \hline \multirow{2}{*}{$\begin{array}{c}R \\
\left(R_{E}\right)\end{array}$} & $\begin{array}{c}\text { Neutral } \\
\text { density } \\
\left(\mathrm{cm}^{-3}\right)\end{array}$ & $50 \mathrm{keV}$ & $75 \mathrm{keV}$ & $100 \mathrm{keV}$ & $125 \mathrm{keV}$ \\
\cline { 3 - 5 } & 1938 & 4.72 & 11.7 & 25.5 & 50.6 \\
2.0 & 891 & 10.3 & 25.4 & 55.4 & 110 \\
2.5 & 514 & 17.8 & 44.0 & 96.0 & 191 \\
3.0 & 310 & 29.5 & 73.0 & 159 & 316 \\
3.5 & 204 & 44.9 & 111 & 242 & 481 \\
4.0 & 106 & 86.4 & 214 & 467 & 926 \\
5.0 & 64 & 144 & 356 & 778 & 1540 \\
6.0 & 42 & 219 & 543 & 1190 & 2350 \\
7.0 & & & &
\end{tabular}

\begin{tabular}{cccccc}
\hline \multirow{2}{*}{$\begin{array}{c}R \\
\left(R_{E}\right)\end{array}$} & $\begin{array}{c}\text { Neutral } \\
\text { density } \\
\left(\mathrm{cm}^{-3}\right)\end{array}$ & $50 \mathrm{keV}$ & $75 \mathrm{keV}$ & $100 \mathrm{keV}$ & $125 \mathrm{keV}$ \\
\cline { 3 - 6 } & 1938 & 3.34 & 2.77 & 2.50 & 2.34 \\
2.0 & 891 & 7.37 & 6.03 & 5.43 & 5.08 \\
2.5 & 514 & 12.6 & 10.4 & 9.4 & 8.8 \\
3.0 & 310 & 20.9 & 17.3 & 15.6 & 14.6 \\
3.5 & 204 & 31.8 & 26.4 & 23.7 & 22.2 \\
4.0 & 106 & 61.2 & 50.8 & 45.7 & 42.8 \\
5.0 & 64 & 102 & 84.7 & 76.2 & 71.4 \\
6.0 & 42 & 155 & 129 & 116 & 109 \\
7.0 & & & & \multicolumn{5}{c}{$O^{+}$} \\
\hline
\end{tabular}

Charge exchange cross-sections were taken from Smith and Bewtra (1978). Neutral hydrogen density was calculated from the Chamberlain model using the best fit parameters of Rairden et al. (1986). $T=1050 \mathrm{~K}$, exobase density equal to $44000 \mathrm{~cm}^{-3} ; r_{c}=1.08 R_{E} ; r_{s c}=3.0 r_{c}$ (from Hamilton et al., 1988). 
different phases of geomagnetic disturbances, considering different criteria for each phase. Pudovkin et al. (1988) studied Dst variation and its dependence on solar wind parameters, and the difference in the decay time $\tau$, for each geomagnetic storm phase. We use their criteria to estimate $\tau$ in the main phase of the disturbance when there is an energy input to the ring current; we consider then values of the ring current decay computation (Dst index recovery) to calculate $\tau$ in the recovery phase.

Pudovkin and co-workers have calculated the rate of energy input to the ring current, $Q$ $(=\partial D / \partial t+D / \tau)$ in the main phase and compared $Q$ with the injection functions corresponding to the $E_{Y}$-component of the solar wind electric field: $v\left(0.5 \sigma-B_{Z}\right)$ ( $v$ is the solar wind speed, $B_{Z}$ is the north-south component of the IMF, and $\sigma$ is the IMF variability). Then they obtain the respective dependence between $Q$ and the injection function; at last, using the fact that at the moment of the Dst maximum intensity, $d D / d t=0$ and then $Q=|D|_{\max } / \tau_{m}$, where $\tau_{m}$ is the characteristic decay time.

For this purpose, during the six periods indicated in table I, 792 -h intervals in the main phase were selected. The $Q$ values and the injection function, determined for a $1-\mathrm{h}$ prior period, were estimated for those periods. The respective dependence is:

$$
Q=4.87+3.49 v\left(0.5 \sigma-B_{z}\right) 10^{-3}
$$

where $v$ is in $\mathrm{km} \mathrm{s}^{-1}, B_{z}$ and $\sigma$ are in $\mathrm{nT}$, $v\left(0.5 \sigma-B_{z}\right)$ is in $\mathrm{mv} / \mathrm{m}$ and $Q$ is in $\mathrm{nT} / \mathrm{h}$. Then we calculated $Q$ an hour prior to the $|D|_{\max }$ and we found $\tau_{m}$ for the different main phase disturbance periods. Figure 2 shows the ring current decay time in the main phase vs. $|D|_{\max }$ and it can be seen that $\tau_{m}$ is practically independent of $|D|_{\max }$ its mean value being around $5.5 \mathrm{~h}$ for $|D|_{\max }>80 \mathrm{nT}$.

For the recovery phase of the different disturbances we calculated $\tau, \tau_{R}$, using the values of the ring current decay calculation (Dst index recovery):

$$
D=A e^{-t / \tau_{R}}
$$

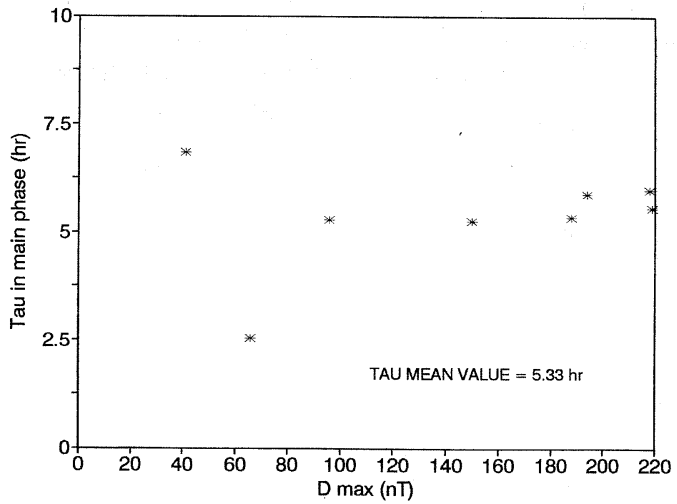

Fig. 2. The ring current decay time in the main phase vs. $|D s t|_{\max }$.

from which we obtain,

$$
\tau_{R}=\left(t_{2}-t_{1}\right) / \ln \left(D_{1} / D_{2}\right)
$$

Using these criteria, we estimated the ring current decay time for the disturbed periods indicated in table I. Afterwards we calculated the parameter $U_{T}\left(U_{T N U}\right)$. $U_{T N U}$ was not calculated for periods where, 1) we did not have enough data, or 2) there was additional energy input to the ring current in the recovery phase.

Figures 1a-f also show $U_{T N U}$. It can be seen that $U_{T N U}$ values are smaller than $\in$ for all periods. The new $\tau$ estimated values are indicated in table III. Those values are comparable with $\mathrm{O}^{+}$and $\mathrm{H}^{+}$charge exchange lifetimes (table II).

So far, we have only taken into account the structure of $U_{T}$, without considering if $\epsilon$, as given by (1.1), is formed by parameters that have been correctly estimated. Looking at (1.1), it is reasonable to believe that the weakest point resides in the estimation of $l_{0}$, the Chapman-Ferraro distance. In an additional approach, and following Roederer (1987), we calculated $\epsilon$ for a $l_{0}$ variable and given by (1.3). The new values of $\in\left(E P_{v}\right)$, together with those for $l_{0}=$ constant $\left(E P_{c}\right)$ and $U_{\text {TVAS }}$ are presented in fig. 3a-f. Now, $E P_{v}$ is greater than $E P_{c}$, approaching more to $U_{T V A S}$ but farther from $U_{T N U}$. 
Table III. Estimated $\tau$ values using the proposed criteria.

\begin{tabular}{|c|c|c|c|}
\hline Disturbance & Phases & Periods $\left(U_{T}\right)$ & $\tau(\mathrm{h})$ \\
\hline $29-30 / 1 / 1978$ & $\begin{array}{l}\text { Main } \\
\text { recovery }\end{array}$ & $\begin{array}{l}01 \mathrm{TU}-16 \mathrm{TU} \\
17 \mathrm{TU}-03 \mathrm{TU}\end{array}$ & $\begin{array}{l}5.3 \\
3.3\end{array}$ \\
\hline $30-31 / 1 / 1978$ & $\begin{array}{l}\text { Main } \\
\text { recovery }\end{array}$ & $\begin{array}{l}\text { 03TU-12TU } \\
12 \mathrm{TU}-14 \mathrm{TU} \\
14 \mathrm{TU}-22 \mathrm{TU}\end{array}$ & $\begin{array}{r}5.3 \\
8.1 \\
21.8\end{array}$ \\
\hline $29-30 / 8 / 1979$ & $\begin{array}{l}\text { Main } \\
\text { recovery }\end{array}$ & $\begin{array}{l}\text { 09TU-18TU } \\
\text { 19TU-20TU } \\
\text { 21TU-02TU } \\
\text { 02TU-24TU }\end{array}$ & $\begin{array}{r}5.3 \\
6.6 \\
10.4 \\
26.0\end{array}$ \\
\hline $20-22 / 10 / 1981$ & $\begin{array}{l}\text { Main } \\
\text { recovery }\end{array}$ & $\begin{array}{l}\text { 14TU-20TU } \\
\text { 20TU-22TU } \\
\text { 22TU-08TU } \\
\text { 11TU-20TU } \\
\text { 01TU-05TU } \\
\text { 05TU-09TU }\end{array}$ & $\begin{array}{r}5.9 \\
6.3 \\
65.4 \\
15.8 \\
110.0 \\
9.0\end{array}$ \\
\hline $22-23 / 10 / 1981$ & $\begin{array}{l}\text { Main } \\
\text { recovery }\end{array}$ & $\begin{array}{l}\text { 09TU-18TU } \\
\text { 19TU-24TU }\end{array}$ & $\begin{array}{r}5.3 \\
37.0\end{array}$ \\
\hline $01-02 / 3 / 1982$ & $\begin{array}{l}\text { Main } \\
\text { recovery }\end{array}$ & $\begin{array}{l}\text { 14TU-06TU } \\
\text { 07TU-24TU }\end{array}$ & $\begin{array}{l}5.6 \\
9.0\end{array}$ \\
\hline $23-24 / 11 / 1982$ & $\begin{array}{l}\text { Main } \\
\text { recovery }\end{array}$ & $\begin{array}{l}\text { 13TU-00TU } \\
\text { 00TU-05TU } \\
\text { 06TU-09TU } \\
\text { 09TU-12TU }\end{array}$ & $\begin{array}{r}5.3 \\
17.4 \\
92.5 \\
5.5\end{array}$ \\
\hline $24-25 / 11 / 1982$ & $\begin{array}{l}\text { Main } \\
\text { recovery }\end{array}$ & $\begin{array}{l}\text { 12TU-18TU } \\
\text { 19TU-23TU } \\
\text { 24TU-17TU } \\
17 T U-24 T U\end{array}$ & $\begin{array}{r}5.3 \\
15.7 \\
26.7 \\
63.0\end{array}$ \\
\hline $10-11 / 2 / 1984$ & $\begin{array}{l}\text { Main } \\
\text { recovery }\end{array}$ & $\begin{array}{l}\text { 10TU-22TU } \\
\text { 24TU-05TU }\end{array}$ & $\begin{array}{r}5.3 \\
17.0\end{array}$ \\
\hline $12-13 / 2 / 1984$ & $\begin{array}{l}\text { Main } \\
\text { recovery }\end{array}$ & $\begin{array}{c}\text { 20TU-07TU } \\
\text { Not calculated. There }\end{array}$ & $\begin{array}{l}5.3 \\
\text { energy input }\end{array}$ \\
\hline
\end{tabular}

\section{Conclusions}

In this preliminary paper a few methods of ring current decay time computation were examined and compared with a new proposal. This new method comes from the need to eliminate the discrepancy between $\in$ and $U_{T}$ values, whose computation gives unreasonable results from a physical point of view (energy dissipated, $U_{T}$, larger than injected energy, $\epsilon$ ), for absolute values of the Dst geomagnetic index greater than $90 \mathrm{nT}$.

This new approach estimates the total magnetospheric energy dissipation parameter, $U_{T}$, with results perhaps better justified from the physical point of view; but now too small to be 


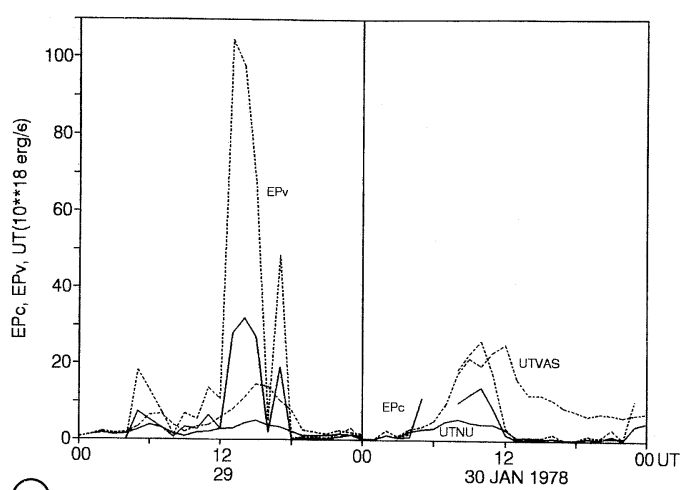

(a)
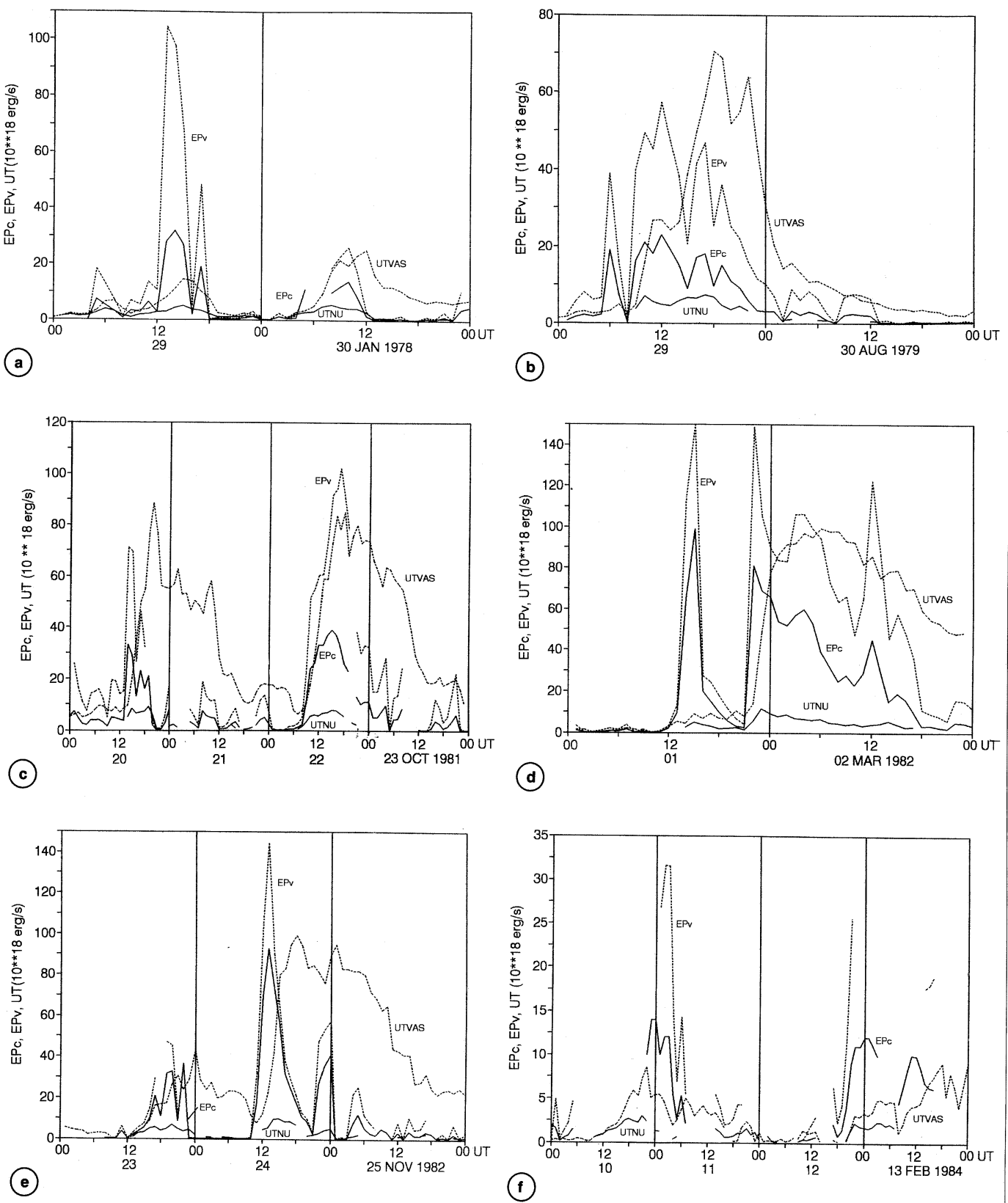

Fig. 3a-f. $\varepsilon$, with $l_{0}$ constant $\left(E P_{c}\right)$; $\varepsilon$, with $l_{0}$ variable $\left(E P_{v}\right)$ and the parameters $U_{T V A S}$ and $U_{T N U}$ for: a) January 29-30, 1978; b) August 29-30, 1979; c) October 20-23, 1981; d) March 1-2, 1982; e) November 23-26, 1982; f) February 10-13, 1984. 
easily accepted. This result is obtained with what we think is a better estimation of the ring current decay time, $\tau_{R}$.

To check the consistency of the function that allows us to calculate the energy injected into the magnetosphere, a variable $l_{0}$ was introduced in the computation of $\in$. This criterion leads to an increased $\epsilon$, but still smaller than $U_{T}$, except $U_{T N U}$, for some of the disturbed periods.

It is difficult to arrive at an adequate conclusion that could be considered correct to explain the mutual interplay between the injected and the dissipated energies. No doubt that for $U_{T N U}$, consideration of the energy carried along by the plasmoids in the antisolar direction is lacking, but the answer is unattainable until adequate measurements are made at the magnetotail. On the other hand, rate of injected energy, which, up to now, is given by different expressions that only represent laws of proportionality with an unknown factor should be adjusted and included in any computation of the input energy.

\section{REFERENCES}

AKAsOFU, S.-I. (1981): Energy coupling between the solar wind and the magnetosphere, Space Sci. Rev., 28, 121.

Gonzalez, W.D., B.T. Tsurutani, A.L. Gonzalez,
E.J. SMith, F. TANG and S.-I. AKasofu (1989): Solar wind-magnetosphere coupling during intense storms (1978-1979), J. Geophys. Res., 94, 8835.

Hamilton, D.C., G. Gloeckler, F.M. Ipavich, W. StüdemanN, B. Wilken and G. Kremser (1988): Ring current development during the great geomagnetic storm of February 1986, J. Geophys. Res., 93, 14343.

Mishin, V.M. (1991): The magnetogram inversion technique: applications to the problem of magnetospheric substorms, Space Sci. Rev., 57, 237.

Perreault, S. and S.-I. AKasofu (1978): A study of geomagnetic storms, Geophys. J. R. Astron. Soc., 54, 547.

Pudovkin, M. I., A. Grafe, S.A. Zaitseva, L.Z. Sizova and A. V. Usmanov (1988): Calculating the Dst-variation field on the basis of solar wind parameters, Gerlands Beitr. Geophys., Leipzig, 97, 525.

RAIRdEN, R.L., L.A. FrANK and J.D. CRAVEN (1986): Geocoronal imagining with dynamics explorer, J. Geophys. Res., 91, 13613.

RoEDERER, J.G. (1987): Magnetospheric processes, Spring College on Geomagnetism and Aeronomy, ICTP, Trieste, Italy.

Smith, P.H. and N.K. BewTRA (1978): Dependence of the charge exchange lifetimes for ring current ions, Space Sci. Rev., 22, 301.

VASYLIUNAS, V.M. (1987): A method for evaluating the total magnetospheric energy output independently of the $\in$ parameter, Geophys. Res. Lett., 14, 1183.

Zwickl, R.D., L.F. BARGatze, D.N. BAKer, C.R. Clauer and R.L. MCPHERron (1987): An evaluation of the total magnetospheric energy output parameter, $U_{T}$, in Magnetotail Physics, edited by A.T.Y. Lui (Johns Hopkins University Press, Baltimore, Maryland), 155-159.

(received May 10, 1994; accepted March 21, 1995) 